\title{
Brokerage at the science-policy interface: from conceptual framework to practical guidance
}

\author{
Peter D. Gluckman (10 ${ }^{1 凶}$, Anne Bardsley (1) ${ }^{1} \&$ Matthias Kaiser (D ${ }^{2}$
}

This article analyses the conceptual framework of brokerage at the science-policy interface as an important boundary function to support trusted and transparent government decisionmaking. Policymaking involves a broad range of considerations, but science advice and evidence is critical to help inform decisions. However, mechanisms for requesting and receiving advice from the scientific community are not straightforward, considering that the knowledge needed generally spans multiple disciplines of the natural and social sciences. Once evidence has been appropriately synthesized, there remains the need to ensure an effective and unbiased translation to the policy and political community. The concept of knowledge brokerage revolves around an understanding of the ontologies, cultures and languages of both the policy community and the science community, in order to effectively link the two bidirectionally. In practical terms, this means ensuring that the information needs of the former are understood, and that the type and form of information offered by the latter aligns with those needs. Ideally, knowledge brokers act at the interface between researchers/ experts and decision-makers to present evidence in a way that informs policy options but does not determine policy development. Conceptually, negotiating this interface involves acknowledging that values are embedded in the scientific process and evidentiary synthesis, and in particular, in considering the inferential risks inherent in making evidence claims. Brokers are faced with navigating complex policy dynamics and balancing information asymmetries between research providers and users. Building on the conceptual analysis and examination of the nuances of brokerage observed in practice, we propose a set of guidelines to translate the concepts of brokerage to practical application.

\section{Introduction}

- he ways in which science and research have been engaged to support government decision-making have evolved over the last 80 years, and today are represented by a wide variety of science advisory mechanisms and ecosystems. Yet, as COVID-19 has illustrated, many ad hoc mechanisms have had to be created, and the way evidence has been inserted into the policy process has been highly variable. ${ }^{1}$ The interface between science and policy is complex, but can be bridged by a particular class of boundary function (Boswell, 2018), known as knowledge brokers, who translate the different languages of the two communities and align

\footnotetext{
${ }^{1}$ Koi Tū: The Centre for Informed Futures, University of Auckland, Auckland, New Zealand. ${ }^{2}$ Centre for the Study of the Sciences and Humanities, University of Bergen, Bergen, Norway. ${ }^{凶}$ email: pd.gluckman@auckland.ac.nz
} 
information needs with outputs. Effective brokerage is first preceded by pluralistic evidence synthesis to provide explanation of the system of interest, and a formulation of options. In theory the brokered advice should be untethered to the values of any of the parties (researchers, experts, broker, or decision maker), and serves to widen and optimize the policy choices of the decision maker. $^{2}$

In this article, we briefly review the history and interrogate the theory of knowledge brokerage for policymaking, and ask how it informs the practice of science advice. It is clear that the advice provided will always consider more than scientific facts, and that policymaking does not necessarily privilege scientific input. We posit that, as a core principle, effective brokerage needs to engage a range of stakeholders in the provision of knowledge and formulation of options-first using evidence synthesis as a form of second-order knowledge co-production. Brokering this knowledge into the policy process requires trust, transparency and integrity. Based on review of the literature and observed and experienced successes and failures, we provide a practical guide for successful brokerage.

The paper begins with a brief background to the use of scientific evidence in policymaking and the evolution of our understanding of science advisory ecosystems. This is followed by a discussion of the boundary functions of evidence synthesis and brokerage, and the importance of distinguishing these elements. The paper then focuses on a more detailed examination of the concept of knowledge brokerage, its core principles, and practical considerations. These concepts, principles and practicalities are then synthesized into a set of 10 recommendations for effective brokerage at the science-policy interface.

\section{A brief history of evidential input}

Before World War II, science was rarely in effective contact with policymaking and the political processes. Policymaking was generally understood to follow Max Weber's idealized bureaucratic theory of public administration, which was based on a managerial model of rational decision-making (Höpfl, 2006). Government administrators were entrusted to act in pursuit of "the common good," and were essentially delegated the task of defining what was in the best interest of the public they served (Beierle and Cayford, 2002). This was done by drawing on scientific evidence and evaluation, and weighing up costs against benefits within the existing legal framework of the State.

In the United States, the concept of the 'scientification of politics' and policymaking, and consequent claims of 'politicization of science' (Weingart, 1999; Hoppe, 1999), emerged in relation to the growth of scientific institutes particularly supporting defence technology, starting with President Eisenhower's appointment in 1957 of a science and technology advisor and a science advisory committee reporting directly to the president (Weingart, 1999). Similar arrangements followed in other countries. The UK appointed a non-political chief science advisor in 1966. In Europe, a range of scientific institutions emerged whose primary responsibility was to provide advice to government agencies on specific technical matters. Decisions were made through the interaction of scientific and administrative 'experts' operating in a top-down manner (Gethmann et al., 2015). This model still partially exists in many countries, but due to the complexities of our modern world and the emergence of Big Science (de Solla Price, 1963) and Mode 2 science (Gibbons, 1994), it has now been supplemented with ever more sophisticated models of science advice at different levels of governance. This extends to the multilateral level-for example, the expanding complexity of the Intergovernmental Panel on Climate Change (IPCC) and the
Intergovernmental Platform on Biodiversity and Ecosystem Services (IPBES) (Beck et al., 2014).

\section{Science advisory ecosystems}

The primary mode of providing science advice within many jurisdictions has now become a function of an ecosystem of commissions, committees, academies, and/or science advisors (OECD, 2015). In different contexts, such advisory mechanisms may proffer advice to legislators, policy communities, ministries and agencies, or the executives of governments, and in some cases, they may also have the role of communication with publics.

Many of these forms of expert advice are based on the idea of policymaking as a linear-rational process, operating unidirectionally from problem identification to problem solution. In its simplest form, such a model assumes that policy goals can be translated into measurable quantitative terms, with decisions based on cost-benefit analysis and economic rationality (Jasanoff and Wynne, 1998). In that framing, advisors would act as 'rational analysts,' presenting authoritative, impartial knowledge and evidence for direct use in decision making (Owens, 2012). This general model relies on an appeal to scientific facts and data for informing policy decisions, based on the theory that better scientific characterization of a problem will lead to better policy. The validity of this assumption has been questioned, as it has been suggested that enhanced scientific knowledge rarely directly resolves policy conflicts (Jasanoff and Wynne, 1998).

It is now well understood that this linear conceptualization does not reflect real-world policy processes (Cairney, 2016), and fails to deal with how knowledge actually enters into policymaking (Jasanoff, 1994; Cairney, 2016). In addition to structured mechanisms for informing policy, knowledge claims are also put forward, solicited or not, by individuals and institutions with various kinds of attachment to decision-making bodies and government. Thus, there often exists a contestation and plurality of ideas, and of access to the decision-making processes.

It is also both simplistic and inaccurate to assume that policy is only informed by expertise from scientific disciplines, as many other considerations are inherent to policymaking (Cartwright and Hardie, 2012; Cairney, 2016). While scientific knowledge dominates some areas of policymaking, clearly the source and character of knowledge used varies depending on the policy context. In some contexts controversies arise because of contestation regarding the validity of different types of knowledge (Grundmann, 2017), and in any case, values can never be fully separated from knowledge inputs. Values are always embedded within the descriptive component of knowledge production-in the choice of question to study, the mode of study, and in the inferential gap between findings and conclusions reached (Rushefsky, 1984; Douglas, 2009; Rudner, 1953).

\section{Critical boundary functions-evidence synthesis and brokerage}

To help resolve the complexities inherent in the science-policy interface, boundary actors and organizations are needed to bridge the divides between different knowledge communities and policymakers. The skills needed for boundary functions to operate well have been discussed extensively in the management and public policy literature (e.g. Boswell, 2018; Zhao and Anand, 2013; Williams, 2002; Tushman and Scanlan, 2017). A number of scholars have specifically considered issues at the science-policy interface from a conceptual perspective (e.g. Jasanoff, 1994; Hilgartner, 2000, 2004; Hoppe, 2005). However, these authors have not parsed the process of transfer of expert knowledge to the policy community. We would posit that there are two distinct processes that need to be explored, each with their own 
methodological, behavioural and normative components: evidence synthesis and knowledge brokerage. These may be undertaken by the same or different entities. The arrangements may also vary according to the issue at hand (Gluckman, 2018).

Authoritative evidence synthesis, involving rigorous evaluation and integration of knowledge from multiple disciplines and perspectives, is critical to inform effective and trusted brokerage. To be useful for policy purposes, knowledge from a range of sources and epistemologies must be integrated in an understandable form that summarizes what is known and what is not known, and conveys levels of uncertainty and other caveats regarding such knowledge. Evidence synthesis can take many forms, from formal meta-analyses to literature review, or to constructing mathematical models to describe a system. In healthcare, evidence synthesis has been framed as a relatively straightforward process in which evidence can be objectively graded for decision making (Welton, 2012; Dias et al., 2013), and while this idea has significant faults even within medical practice (Atkins et al., 2004; Bagshaw and Bellomo, 2008), it is significantly more complex when used in other domains for informing public policy (Gough et al., 2019). Transdisciplinary insight and skills are needed to recognize and deal with tensions between robust evidence, values-based positioning, and normative arguments. Lessons can be learned from the field of postnormal science (Funtowicz and Ravetz, 1993), which describes situations where complex science intersects with public values that are, by definition, likely to be in dispute.

Particular skills are required to ensure appropriate unbiased assessments, and to deal with the challenges of incorporating inputs from all relevant disciplines. Clearly there are judgement calls as to the range of experts involved. It is beyond the scope of this paper to focus on how the authority of knowledge is established, noting the extensive scholarship on that issue (Jasanoff, 1994, 2003). Research that exists within siloed science disciplines is of limited value in informing publics, policymakers and politicians, who need to take social and other values and perceptions into consideration. The social sciences are therefore of critical importance, but their inclusion within these science advisory ecosystems is only a recent phenomenon (Kropp and Wagner, 2010; Matthews, 2020). In COVID-19, the transparency in public science has been variable, particularly in regard to social science input into early epidemiological models (Bertozzi et al., 2020; Metzler, 2020).

While distinct from the generation of new knowledge, in synthesizing evidence from a range of expert and stakeholder perspectives, such boundary roles serve to facilitate second-order knowledge production, and its transmission to policy and general audiences. Engaging the policymaker and stakeholders in coidentification, and in some situations co-production of the knowledge needed can help to ensure it is useful and used, as has been supported by research in environmental and climate policy (Lemos and Morehouse, 2005). Engagement of this sort provides something akin to what Guston refers to as 'collaborative assurance' that enhances societal benefit of public decision making (Guston, 2000).

\section{The knowledge brokerage function}

Even when skillfully executed, evidentiary synthesis on its own tends to have little direct impact on public policy. Knowledge brokerage in its most simplistic description is the process of effectively transmitting the results of evidence synthesis to the policymaker. In doing so the broker must take into account the dynamic nature of policymaking, and the epistemic and nonepistemic value-based perspectives of both providers and users of knowledge. Both evidence synthesizers and brokers need to be reflexive, considering any impact their own values might have on the processes they undertake.

The publication of Roger Pielke's book The Honest Broker in 2009 (Pielke, 2007) brought the theoretical issues regarding this interface to the attention of the scientific boundary community. Since then, the term 'broker', or 'knowledge broker' has been extensively used, albeit with diverse interpretations, in discussions of science advice to policymakers. Brokers are defined as intermediaries, negotiators, or interpreters between parties who may not otherwise easily understand each other. However, there has been little consideration of the actual practice of brokerage at the science-policy interface. For some in academe and in academies, the term seems to be simply 'policy-speak', and thus of little utility in the absence of a clear framework for conduct.

Conceptually, the science-policy interface can be parsed into several categories of conduct. Pielke (2007) describes four idealized categories or roles of scientists in their interaction with the policy community. Most interest has focused on his distinction between the 'issue advocate' and what he termed the 'honest broker of policy alternatives'. The third category was the 'science arbiter', which Pielke describes as having a narrow technocratic focus on questions that science can answer explicitly, and does not seek to influence the direction of policy. Generally, science arbiters comprise a science team within an agency, a committee or an academy tasked with answering the question posed, while staying away from the policy and political implications. Regulatory science is intended to have this characteristic, focusing on the quality and sufficiency of evidence irrespective of the policy implications, although in some jurisdictions that independence can be compromsied (Ennser-Jedenastik, 2016). The fourth category of pure scientists refered to those who did not engage with the policy community. Later Pielke was to imply a fifth category-the stealth advocate, to describe those who use science communication to advance a 'hidden agenda' (Pielke, 2015), reminiscent of some arguments raised in discussing Hilgartner's construct on the contested credibility of science (Hilgartner, 2000, 2004).

The issues advocate. The issues advocate is not generally appropriate as an institutionalized boundary function. Exceptions may be scientific bodies designed to pursue a special agenda, such as the policy functions of fisheries research. Scientists or groups acting in this capacity often provide evidence synthesis, but its presentation is generally designed to achieve a specific agenda or programmatic outcome rather than to offer non-directional support. These groups or individuals can, however, influence policy decisions indirectly through their advocacy and impacts on public opinion. In particular, they can set the stage for the political agenda, and awareness among politics where action is needed. Within limits, this is a very proper function for individual scientists and scientific organizations (Stenek, 2011). ${ }^{3}$ Climate change policy has been advanced through such activities (Pierson, 2012).

Issues emerge when strong advocacy does not coincide with the scientific consensus, often with so-called experts operating outside institutions of science advice and in fields distant to their expertise, yet relying on their status as scientists to propel their advocacy. As Oreskes and Conway demonstrated in their well-researched book Merchants of Doubt (Oreskes and Conway, 2010), individual scientists operating out of scope of their expertise have been unethically coopted to serve commercial interests, at times in diametric opposition to public interest and the scientific consensus on a number of critical issues. Often the tactic is to misrepresent scientific uncertainty to undermine consensus views. This is a challenge for the broker, in that scientific uncertainty is a given for any issue on which science advice is sought. It is an obligation of 


\section{Box 1 - I Defining brokerage}

Brokerage at the science-policy interface can be defined as a form of boundary function that generally has the following attributes:

- It ensures alignment between the needs and/or request of the policy community (or other audience) and the evidence synthesis provided.

- It ensures that any evidence synthesis is robust, transdisciplinary, and has had appropriate expert inputs.

- It ensures that the policy community and other audiences have a robust understanding of the implications of the evidence proffered.

- Where appropriate, advice is provided in the form of choices/options rather than making specific recommendations.

- Where policy advice is required, it is provided in a manner that minimizes the biases and values of those providing advice, and the advice is self-reflexive in that it communicates its own limitations and any unavoidable bias.

- It does not attempt to take a role in the policy choice process.

scientists to be transparent about uncertainties and explaining them clearly when forming advice.

The honest broker. Quite distinct from the issues advocate, the 'honest broker' is described by Pielke (2007) as a person or group of persons who put personal biases and values aside in order to assist policymakers in making choices between options, generally by providing clarity on the evidence.

There are many dimensions to the role of a broker at the science-policy interface. An analysis by the European Commission's Joint Research Centre (JRC) of insights from work at the interface defined knowledge brokers as a type of expert, possessing the essential skills "beyond simply communicating evidence, towards identifying options, helping policymakers understand the likely impact of choices, and providing advice from a scientific viewpoint" (Topp et al., 2018). The report highlighted the conflict between Pielke's concept of 'honest broker' and the need to consider the political context in which evidence is presented and used. A challenge is how to do so without the raising concern about the politicization of knowledge, which has been long emphasized by Jasanoff (1994) and others.

The JRC report also points to the important role of brokers in helping to increase policymakers' demand for evidence (Topp et al., 2018). An essential role of the broker is to understand the information needs of the policymaker, even when it may not be clear to policymakers themselves. Once that is determined, the broker must ensure that the required evidence is gathered and synthesized in a robust manner, and that the information is communicated in a way that acknowledges all of its dimensions and depths, yet is understandable to the audience. In the role of honest broker, this process leaves policymaking to the policymaker, and political decisions to the politician, minimizing any impact of the broker's own biases. Generally, this means providing options rather than a single path ahead, but at times the broker will confront tension with the desire of policymakers for specific recommendations (Topp et al., 2018).

While brokers and boundary spanners cannot claim, and need not have, universal expertise (Williams, 2002), they must be expert and trusted translators of science to policy, and of policy needs to the science community. The latter is distinct from the role of advice on science policy per se, and indeed there is a danger that it can undermine confidence in the brokerage role if it raises the impression that the advice is tailored to influence research funding (Gluckman, 2014). The brokerage role is not simply an add-on to a scientist's normal role, but rather requires skill and training to understand the interface. It demands and indepth understanding of both the scientific question (and ability to interpret multiple types of evidence) and the needs of the audience to which the evidence must be communicated.

Critically, the broker must be trusted as neutral, not as a lobbyist for a particular policy direction. There are many examples of scientists using their scientific credibility to selectively highlight policy options (Scheufele, 2014) - this is not a the role of the broker we outline here. Policymaking at its heart requires making choices between different options affecting different groups of stakeholders in different ways, and there are always trade-offs to be made (Gluckman, 2017). While robust evidence helps focus those choices, the many other considerations of public policy-economic, prioritization, societal, diplomatic and political-are beyond the direct scope of brokerage. Nonetheless, the broker will need to be aware of the potential for these factors to influence uptake of evidence-informed policy options.

The criteria that we use to define the science-to-policy brokerage role are outlined in Box 1. These criteria make it clear that the broker is not the mouthpiece of science in general, nor do they simply convey a consensus of a majority within the scientific community. A broker respects a majority scientific consensus, ${ }^{4}$ but using judgement, may also need to communicate divergent viewpoints to the extent that they are scientifically supported by some acceptable evidence. In other words, they must acknowledge where there is legitimate debate (National Academies of Sciences, 2017). The broker may have to help the policymaker navigate through such discord (Hoppe, 1999). Governments cannot be expected to referee a scientific debate, and almost always need to make decisions in absence of conclusive evidence. The broker can assist by helping to determine the sufficiency of evidence, or advise the need for precaution where evidence may be insufficient. Douglas's concept of inferential risk becomes critical in such contexts (Douglas, 2009). Brokers may be asked to undertake other functions, such as the evaluation of a specific option or action, or to engage with other audiences, and in all cases similar principles apply.

\section{Core principles}

The actions of the broker must be underpinned by the core principles of trust, transparency and legitimacy, a respect for diverse knowledge systems and epistemologies, and acknowledgement of the inherent role of values in the process. These are expanded on here.

Trust, transparency and legitimacy. To be effective, the institutions of brokerage must be trustworthy to the political, policy, public and scientific communities (Williams, 2002; Gluckman, 2014; Tushman and Scanlan, 2017). Brokers are connected to both science and policy worlds, but will not be effective if they are seen as peripheral or marginal to one or the other community (or both), and therefore viewed with suspicion.

A significant portion of effective brokerage may come in the form of informal discussion, particularly early in the policy process or when seeking alignment of question and answer. In these cases, political and policy sensitivity may limit communication, and premature exposure can undermine trust. Brokers who are institutionally linked to the policy community will be called on frequently for informal advice, either verbally or where an almost instant response is needed. Most frequently this occurs when policy development is embryonic and sensitive, and where 
science can be particularly informative, but it may also occur with some urgency in emergency situations like a pandemic. In such situations others may be called on to take this role, but the principles remain the same. Only some forms of broker, for example the science advisor or a high-level commission, are likely able to have such informal and repeated access; this is one distinction between jurisdictions with such systems and those that rely largely on their scientific academies (Gluckman, 2014).

Transparency of advice is one way in which trust can be sustained, and allows for post-hoc extended peer review (Jasanoff, 2006). However, such transparency is effectively limited to formal reports and policy briefs provided to, or prepared by the broker. In general, most brokerage institutions use some form of peer review for such refined products. But an effective broker, if institutionalized, can be transparent in broader ways such as through accessibility to the media.

It is clear that many of the actors involved in requesting advice also form views independent of any brokerage system. In this regard the broker needs to be particularly alert to the risk of advocacy-based information or 'policy informed science' that may need to be addressed. (Marmot, 2004; Hunter, 2016).

Respect for diverse knowledge systems. Scientific evidence is not the only form of evidence that publics and their political representatives consider. Science is distinguished in its claims of robustness through organized criticism and skepticism, and particularly through validation by repetition, but anecdote and personal observation are also sources of evidence within the political arena. Indigenous and local knowledge provides other sources of potential evidence. The broker must be sensitive to these other forms of knowledge and how they may impact on the shaping of advice. This introduces a further element into brokerage: acknowledging, listening to, and respecting a variety of knowledge sources and their approach to the problem at hand, evaluating the options implied by these knowledge sources, and assessing how effective they will be, including the degree to which they will be socially robust.

Acknowledging values and biases. It is now well accepted that science is not free of values (Douglas, 2009). However, the processes of science are designed to minimize the impacts of the scientist's personal values and bias on the collection and analysis of data. But even then, the sampling, use and interpretation of evidence is always values-dependent. Pielke's description of an ideal world in which the broker would be immune from considering their own values, worldviews and biases needs to be appreciated as what it is: a normative ideal which we can never fully live up to (Pielke, 2007; Douglas, 2009). Nevertheless, wellconducted evidence synthesis and brokerage must try to approach a bias-free analysis, and the broker must acknowledge community values in what is synthesized and transmitted.

It is up to the policy community to layer community, societal and political values into policy decisions. What is crucial in this regard is the integrity of the broker. Trust can only be maintained if the broker as a person or as a committee is perceived of-and actually operating under-a moral integrity which respects viewpoints, even if they are not shared.

\section{Who can be brokers?}

Brokerage likely needs to be institutionalized and formalized if it is to be effective on more than a singular issue. The alignment of need and provision cannot otherwise be developed, and the processes needed for effective brokerage will not be achieved. Further, without formalized access to the policy community in a way that can respond to their demands and early speculative discussions, the ability to be part of the original exploration and framing of a possible question or policy action cannot happen. Yet, this is when scientific input is likely of most value and effect.

While Pielke saw brokerage primarily as being a group activity (Pielke, 2007), practicalities mean that it is most likely that 'institutionalized' or mandated individuals actually act as the broker, provided that they are supported by processes that ensure that the principles of disciplinary coverage and evidentiary synthesis are followed. The mandated individual may be a government science advisor supported by a team, a chair of a commission or committee, or president of an Academy (in those countries where academies are the major route to advice). In each case the broker must have early enough access to impact on policy framing, and repeated access to see if the understandings are reflected in policy development. On singular issues, whether a scientific body, an apolitical thinktank or expert is interfacing with the policy community, similar principles apply.

Situating the broker within the science advice ecosystem. Where accepted and recognized institutions of brokerage are not in place, there is a danger of competition by scientists for access to policymakers (Oliver and Cairney, 2019). There is often a lack of recognition of the breadth of expertise needed, and therefore a failure of scientific inputs to have policy impact. The competition for access can negatively affect the collegiality of science and the promotion of interdisciplinary science. A brokerage system of 'boundary spanning' activities (Bednarek et al., 2018) can assist significantly in creating a path to impact from science, and equally assist the science community in identifying areas where science can preemptively assist in policy. That is not to imply that institutional brokerage has or should have either a monopoly on advice or access, but it may explain why different jurisdictions have not adopted the science advisory model that includes institutionalized scientific advisors.

Different countries have established different "cultures" of advice and influence. This holds true not only for the interface between politics and science, but also for the interaction among different ministries and governmental agencies (Jasanoff, 1994). Whether science advisors, commissions or academies are best placed to have the brokerage role depends on the constitution and approach to policymaking in each country. For example, in some countries legislators have a significant role in the early formulation of policy, in others it is largely the executive of government in partnership with the policy apparatus. A key issue for effectiveness is whether the brokerage institution has ongoing access into the policy process or can only impact at a single point. Many scientific academies essentially only have a role at a singular point in the policy process.

It is clear that no singular system is adequate to fulfill the full range of brokerage roles. A comprehensive science advisory ecosystem includes knowledge generators, knowledge synthesizers, knowledge brokers and, given the important role of publics, knowledge communicators (see Table 1 (modified from Gluckman, 2018)).

Brokerage and science diplomacy? This discussion has focused on the interface with the policy process, and primarily on the interactions between the expert community and the politicalpolicy machinery in a jurisdiction-whether local, state or national. More complexity lies in dealing with policies and actions set at the international level. Here diplomatic and national interests have largely created processes that make evidence brokerage difficult (Kohler, 2020). International assessments such as those performed by the IPCC involve elaborate methods for evidence synthesis, but the actions that follow depend primarily on domestic interests and thus ultimately devolve to a 
Table 1 Highlights the roles of different actors within science advisory ecosystems.

Different roles in a science advisory ecosystem

\begin{tabular}{lllll}
\hline & Knowledge generators & Knowledge synthesizers & Knowledge brokers & Science communication \\
\hline Individual academics & +++ & ++ & & ++ \\
Academic societies/professional bodies & & ++ & & ++ \\
Government employed practicing scientists & +++ & + & + & + \\
Scientist within regulatory agency & + & +++ & + & + \\
Independent think tanks & & +++ & + & ++ \\
What works units etc. & & +++ & +++ & ++ \\
National academies & ++ & ++++ & ++ \\
Government advisory boards/science councils & & ++ & ++ \\
Science advisors to executive of govt & & + & ++ \\
Science advisors to legislators & & & ++ \\
\hline
\end{tabular}

jurisdiction. This requires greater alignment between national mechanisms of science advice and those of global bodies (OECD, 2015,2018 ). Those agencies that have science advisors (e.g. the World Health Organization [WHO] and the United Nations Environment Programme [UNEP]) may allow for a greater engagement in the practice of brokerage. But generally, an emerging challenge in science diplomacy is how to create more effective brokerage between the science and policy communities in the multi-lateral context.

\section{Time frames for advice-immediate vs. strategic}

We have seen in the COVID-19 pandemic the speed with which the research community is able to respond to an information need (Zhang et al., 2020), as evidenced by the flooding of preprint servers with (often non-peer-reviewed) research outputs (Kupferschmidt, 2020). It is less clear how this new information is filtered for robustness and finds its way into timely policy advice.

A large part of effective management of this global crisis depends on the level of preparedness for a crisis of this type and magnitude (Lewis, 2020). This is where long-term thinking comes in. In some countries, science advice has argued for building up structures that can cope with crises of these dimensions, expressed via national risk registers or other mechanisms (Tyler and Gluckman, 2020). Many issues policy makers will confront involve technology assessment, horizon scanning and anticipation. Contextual change due to environmental, social and economnic change adds further complexity. Increasingly, scientific advice is critical to policy choices made as nations navigate these uncertain futures.

Science brokerage is thus desirable, if not essential, both in regard to issues of immediate relevancy, but also on issues of long-term policies and preparedness. The challenge lies with both sides of the interface: while the sciences may have been too complacent and not pushing the issues adequately, the policy side may have had no ear for long-term issues, many of which they did not have on their agenda. Brokerage systems can help address these deficits.

\section{Theory meets practice}

While Pielke (2007) and others have described idealized roles and useful concepts for individuals or groups acting at the science-policy interface, he did not detail how these roles translated to specific conduct. Little in Pielke's writings informs the practicalities for institutions (which may be an individual or a collective) that claim a brokerage role. Given the growing interest in the practicalities of the science-policy interface at a time when the boundaries between reason and values have become increasingly blurred (Davies, 2018), the principles and practicalities of evidence brokerage require scrutiny and review. There are a number of key considerations, which are outlined below.

Interacting with the policy process-timing matters. As noted above, policymaking is not a linear process. How it evolves depends on the complex interactions between the political and policy communities, interest groups, citizens and experts (Hallsworth et al., 2011). Depending on the constitutional arrangements, legislators may have minimal roles or very extensive roles in the initial evolution of policy. Further, policymakers have limited bandwidth and often only lurch to problems when externalities force their attention (Cairney, 2016). Beyond that, the political process favours incremental rather than disruptive change-the latter is more likely to have multiple spillover costs ultimately reflected in electoral outcomes. (Cerna, 2013) Given these considerations, policy development generally only occurs where the problem is of political interest, and where there is a politically acceptable and scalable solution. This is not always the case when science presents issues to the policy community. This has implications for effective brokerage.

Scientific input can be particularly effective when brokers are positioned to play a role in the initial discussions to help frame a particular issue or challenge for policy consideration (Michaels, 2009). This requires the brokerage system to be well-linked to the institutions of policy, particularly when the scientific community have identified an issue, but policymakers have not yet grappled with it in any depth. At this stage the likely form of product is a scoping document assessing what is known and what is not, with less focus on potential options that may emerge. Once the policy or political community seizes on a problem, the focus must be on options and their presentation, bearing in mind that disruptive, non-scalable solutions are unlikely to be accepted (Cairney, 2016).

It is important to realize that scientific contributions to an issue may also come too late in the process. This happens when, for instance, political parties have used an issue to distinguish their policy from that of other political parties. At this point, decision makers are usually only open for supportive evidence to their viewpoint. As soon as parties have gone out publicly with a policy on an issue, all the political dynamics go against openness for change or drawing back from these internal decisions (Marmot, 2004; Sharman and Holmes, 2010). Thus, the policy community or the political process may have already framed the problem and direction of travel before the science community is aware or engaged. If that direction of travel is in line with the evidence, useful input is easier; if it is not, the broker may have to play a diplomatic role to try and shift the direction of travel. This is a challenge requiring both institutional access and a trusted brokerage system. 
Brokerage and public audiences. The key attributes and principles of brokerage (Box 1) can also underlie trusted communication with non-policy audiences, and particularly with publics. Knowledge brokering in this context assumes that enhanced access to knowledge may directly or indirectly lead to positive social outcomes (Oldham and McLean, 1997).

The impact of science on policy is not independent of how publics view the evidence (Jasanoff and Wynne, 1998; Jasanoff, 2004). While advocacy based on science is an important part of the democratic process, and individual scientists can and do speak both as scientists and citizens, there is also a critical role for public-facing evidence brokerage. This may be through the same institutions as for the policy community, or it may be through well-trusted scholars, scientists or science communicators. Indeed, the scientist's contract of trust with the public often depends on adopting the principles of brokerage.

A core issue for science communication to the public is avoiding deficit approaches (Miller, 2001), and acknowledging other (non-science) forms of knowledge. The approach detailed above follows much of the prescription of post-normal science (Funtowicz and Ravetz, 1993), acknowledging that humility and honesty is needed at the interface between complex science and disputed public values.

In recent years there has been an explosion of misinformation, whether willful or not, via search engines, polarized mainstream and social media. Several papers have shown that even on neutral medical topics such as infant sleep position, a large fraction of website information is misleading or wrong (Joyner et al., 2009; Pitt et al., 2016; Moon and Task Force On Sudden Infant Death, 2016). The issues of the post-truth era and its impacts on democracy and policymaking and public understandings and attitudes are well documented by others (Davies, 2016; Speed and Mannion, 2017; McIntyre, 2018). There remains debate and uncertainty as to the best way to counteract this, especially in the public domain (Mair et al., 2019). Various behavioural and decision-science experiments appear both inconsistent and affected by contextual issues (Bardon, 2019). Nevertheless, a trusted knowledge broker should be able to communicate to the public about what information is or is not reliable.

\section{Ten recommendations for effective brokerage}

Our own experience and observations of the wider brokerage landscape, particularly through the International Network for Government Science Advice ${ }^{5}$ has provided learnings on how to effectively apply theory to practice.

A useful approach to brokerage might take account of the following points:

1. Consider the demand side and policy dynamics of the issue: Effective brokerage requires a policy/political customer who wants advice; if scientific information is presented unrequested, it will generally have little impact on policy processes. Some issues of interest to the research community may simply be too early for policy framings, while others may be too late, since political actors have already taken a position. The broker has a valuable role in identifying the appropriate timing for policy advice, and can in some such cases assist by building the case with the policy community to seek input (Office of the Prime Minister's Science Advisory Committee, 2014).

2. Recognize the policy question, purpose and evidence need: From the outset the broker must consider the purpose of the request. Is it a background assessment of knowledge to inform early framing of policy possibilities and to inform the public? Is it to provide options for policy consideration (this being Pielke's primary proposition regarding brokerage)? Or is it to focus on evaluating some particular policy proposal? What is the time frame for response, and where does it fit in the policy process? The broker should be able to discern different conceptual phases in public policymaking: agenda setting, policy development, decision making, implementation, and evaluation (Kropp and Wagner, 2010).

3. Think about the framing-is the right question being asked? When advice is requested from the policy community, it often needs to be reframed to be sure it is answered appropriately and in a way that is useful. A proposition may be advanced by a policymaker without having a clear understanding the state of science and disciplines needed. This sometimes means that the real questions that will be of value to the policy community may be obscure to them. For example, in the case of the New Zealand report on screening of houses for methamphetamine contamination, the question initially put was whether the standards set were appropriate-however when interrogated, the real question was whether any testing was needed at all (Bardsley et al., 2018). The broker has a key role in working with the policy community to ensure the appropriate questions are asked.

4. Assess the evidence base: Effective brokerage relies on careful evaluation of the quantity and quality of available evidence. A starting point must be to ensure that the evidence synthesis integrates all the relevant robust knowledge, and any disciplinary gaps in the evidence should be identified and filled where possible. The depth of the analysis required will obviously depend on context and the question, but, in general, there is always the need to consider both the natural and social science dimensions. The latter are particularly cogent to public policy considerations.

5. Assess the knowledge gaps: Equally important is to recognize the knowledge gaps that always exist in any scientific assessment. In contrast to the arbiter role, where the empirical data is the basis of assessment, the broker assists the policy community in situations where the science will inevitably be incomplete-yet policy choices need to be made. Acknowledging these knowledge gaps also implies a recognition of what Douglas (2000) terms the inferential gap (or 'inductive gap'), and the need to make a judgement about whether the available evidence is sufficient to make a particular claim.

6. Communicate the uncertainties, caveats, and reliability of evidence: Whatever the question under consideration, there will always be limits on the scientific knowledge. Part of the broker's role is to communicate the uncertainties within the data and/or its synthesis. Communicating uncertainties should not focus solely on numbers, probabilities, and statistics, but can use easily comprehensible tools and illustrations, such as the Numerical Unit Spread Assessment Pedigree (NUSAP) scheme (Van Der Sluijs et al., 2005). Depending on the question this may require estimates of probability, assumptions, and discussion of risks. When the data supply is poor or when dealing with yet-untested technological choices, risk discussions will extend from classical probabilities, and focus on qualitative scenarios of best and worst outcomes. Numerical assessments should be supplemented with indices of their reliability and variation.

In this context, the broker must be aware of the extraordinary rhetorical function of numbers and graphswhich can often be taken as factual description and may be inadvertently or purposefully misused. In the current context of an increased density of misinformation in the public arena (Scheufele and Krause, 2019), effective brokerage needs to consider how to respond, particularly 
if the misinformation appears to be impacting on the policy process. There is a danger in the most contested spaces that science may be coopted and used as a proxy for debates which do not have their basis in science (Oreskes and Conway, 2010; Parkhurst, 2017), and the broker must navigate this by explaining the underlying issues.

Consideration of the quality and nature of the evidence are essential to brokerage and synthesis, but beyond that there may be other caveats that need to be included. For example, is the evidence direct or indirect? Is the contextual background of the available evidence appropriate in the context where the advice being offered? Any assumptions that are made should be identified. Good scientific judgement is needed to recognize implicit vague assumptions, incomplete analyses, and missing data in the scientific information.

7. Identify constraints on scientific claims-the inferential gap between knowledge and conclusions. Central to any practice in evidence synthesis and brokerage is a consideration of the 'sufficiency of the evidence' to make conclusions. Whereas scientists can take their time to gather evidence to support a claim, policymakers cannot-they need to make decisions based on incomplete evidence. The broker can assist by reporting degrees of evidential support, but not certainty, to help the policymaker consider the consequences of error in accepting or rejecting the evidence claim. However, the policymaker must ultimately make a value-based judgement about those consequences, essentially using values to bridge the 'inferential gap' between the evidence and conclusion (Douglas, 2009). Science advice must acknowledge that gap and consider its implications, otherwise it can be exploited, for example when scientists' claims of absent (or insufficient) evidence is treated as 'evidence of absence' (e.g. of a risk).

8. Evaluate the level of 'consensus'. Brokerage in the public policy context also requires analysis of disputed science, for which neither policymakers nor politicians can be expected to be scientific referees. If a scientific consensus cannot be reached, firm conclusions are not possible, and the science is less likely to impact on policymaking unless it coincides with predetermined political biases or agendas. Brokers thus have a role in defining the 'consensus' in the face of what we know and do not know, and providing appropriate interpretation to divergent views. This can be crucial for matters at the interface of science and politics, for example in applications of the precautionary principle, where different cautionary strategies may be possible.

9. Understand and communicate the tradeoffs and non-scientific implications: Science brokerage is not about making policy decisions, but rather is about describing the landscape (the complexities of the issue) and then discussing the options (what can one do about it?). The broker needs to be cognizant of the implied positive or negative spillover effects and tradeoffs in any decision made, and where possible, indicate these through linking with different sectors in the policy community. The tradeoffs may have an evidentiary basis that can be analysed, or may be based on normative argument. Virtually every policy measure to tackle complex issues will have costs and benefits, and will impact intangible sociocultural values. Such issues impact people and their perceptions differently, and they may be disputed amongst citizens. While it is not the role of the broker to clearly favour or disfavour any one of the different value views, it is part of the broker's remit to (a) raise awareness about these implications and (b) provide information about implications of the different options affecting these value landscapes. For instance, it might be relevant for a particular policy and ethical assessment to explicitly point out when all costs are externalized, or when benefits are strongly skewed among social groups.

10. Ensure comprehension in the presentational approach: The broker must work with the science community to be sure that information is provided in a way that is useful to the policymaker. Hilgartner (2000) discusses the presentational benefits and risks that accrue in how the interface operates. Pielke's discussion of advocate and broker (Pielke, 2007), and later of the stealth advocate (Pielke, 2015), highlights the importance of considering how the advice might be manipulative-the broker has key responsibilities here if trust is to be sustained. Reports written in the language of the scientific community are often inaccessible to the nonscientist, and while detailed information may be essential for the preparation and evaluation of options, it is not the need of the policy community.

The form of presentation of the evidence may vary from a formal report, to policy brief, to infographic, to oral presentation, according to need and to the specific request. Irrespective of the mode of delivery, a key issue is to ensure that the audience is not overwhelmed by unnecessary information, is not confused by jargon and that the key points are understood. Ensuring each of these is a core role for the broker. For example, in a crisis meeting over an earthquake or pandemic, ensuring comprehensive understandings is critical, and the broker is likely to be an intermediary between the subject expert and the decision maker, often defining the common linguistic framework to be used in the exchange. Adequate communication of risk is a critical component.

These 10 points highlight the reality that the broker is not simply a passive translator between two distinctive cultures of policy and science-there is a need to actively ensure alignment and appropriate framing of query and answer, sometimes there is the need to actively build the request from the policy community, and if necessary work with the expert community to ensure the right engagement of disciplines. Further, the product must be fit for purpose, acknowledging is boundaries and not straying into the decision space. While charting the value dimensions involved in a decision is necessary, the prioritization among these values is not the role of the broker, and should be left to policymaker, whose role is to consider the broader dimensions of policy. In general, the broker's role is not to make specific recommendations-it is to ensure understandings and options and their wider implications.

\section{How is 'effectiveness' determined?}

One of the perpetual questions about science advisory ecosystems is how to assess whether it is effective or not (Owens, 2012). This obviously depends on how 'effective' advice is defined, and from whose perspective-scientist, public, policymaker or politician. Clearly providing an evidentiary analysis of the options and their implications must be of value in jurisdictions where an informed and neutral policy community is accepted as essential to an effective democracy. Part of the challenge is identifying how science advice is incorporated into the complex network of actors from which policy emerges.

COVID-19 demonstrates an urgent need for both pluralistic evidence synthesis and its brokerage, and simultaneously provides a natural experiment as to its effectiveness. The efficacy of science advice is being put to a test on a very short time scale, testing the bounds of evidence quality (Ruggeri et al., 2020). It is still too early to assess the effectiveness of different models of science advice, although such research has started (International Network for Government Science Advice, 2020). The International 
Network of Government Science Advice (INGSA) has developed an Evidence-to-Policy Tracker ${ }^{6}$ to follow developments in policy and strategy in different jurisdictions, and interrogate the science advice and evidentiary inputs used to justify the decisions made. Analysis of the data should help shed light on effective knowledge brokerage as it tracks inputs into policy interventions by various national and sub-national governments around the world.

\section{Conclusion}

Knowledge brokering can be a key enabler of evidence-informed policymaking. This assumes a desire for policy design to be driven by analysis of all the available options, and not by ideology. It is also based on the idea that successful integration of evidence into policy requires the (co-)production of robust evidence to begin with, and its skilful translation for end-users. This has been the subject of extensive theoretical discussion, but relatively little in the relationship between theory and evolving practice. This paper tries to bridge these two perspectives.

Despite the many challenges, a trusted and effective broker at the science-policy interface can play a critical and privileged role in addressing knowledge asymmetries and in clarifying policy options. Brokers help policymakers and the public discern what evidence is reliable. Their position, if close enough and trusted by the policy community and public, can make their intervention particularly effective. We have outlined the principles and criteria for effective brokerage, though we stress that carrying them out is not a simple task. Skillful brokers are indeed rare.

Clearly, the success of brokerage requires a policy-making process that is receptive to evidence-a process that begins with a question rather than an answer. This in turn depends on the state of democracy and the willingness of the political elite to base their decisions on robust realities. Indeed, one may claim that respect for expert knowledge and informed discourse about policy options is the characteristic sign of civil society. In such societies, knowledge brokers will always have a role.

Received: 29 April 2020; Accepted: 18 January 2021; Published online: 19 March 2021

\section{Notes}

1 For a summary of the use of evidence in COVID-related decision making see https:// www.ingsa.org/covid/policymaking-tracker-comparative/.

2 It should be noted that science and research are not 'values free', despite this being the normative ideal (see Douglas, 2009). Brokers must recognize potential biases and values in both evidence generation and synthesis, and in the way questions are posed by the policy community or suggested by the scientific community.

3 Some scientific academies have attempted to address the issue of advocacy in their guidelines (e.g. http://www.scj.go.jp/en/report/Code_of_Conduct_for_Scientists Revised_version.pdf). They developed codes of conduct with the idea that the contributions of the scientific community to government and society are maximized when a consensus voice of scientists is supplied. This does not imply a disregard for minority views - these should be accounted for in the scientific advice, and indeed in some cases presenting diverse viewpoints may be more constructive than presenting a 'conditional' consensus. This is part of the role of the broker.

4 Defining a scientific consensus is never a "democratic exercise" based on simple majority opinion. There are no simple majorities in science, since it all depends on who is considered an appropriate expert and who is consulted. An element of judgement enters here, which inevitably also opens brings in some form of value bias. Thus, ideals of total "objectivity" necessarily fail.

5 www.ingsa.org

6 https://www.ingsa.org/covid/policymaking-tracker-comparative/.

\section{References}

Atkins D, Eccles M, Flottorp S et al. (2004) Systems for grading the quality of evidence and the strength of recommendations I: critical appraisal of existing approaches The GRADE Working Group. BMC Health Serv Res 4:38
Bagshaw SM, Bellomo R (2008) The need to reform our assessment of evidence from clinical trials: a commentary. Philos Ethics Humanit Med 3:23

Bardon A (2019) The truth about denial: bias and self-deception in science, politics, and religion. Oxford University Press, Oxford

Bardsley A, Low FM, Gluckman PD (2018) Methamphetamine contamination in residential properties: exposures, risk levels, and interpretation of standards. Office of the Prime Minister's Chief Science Advisor, Auckland

Beck S, Borie M, Chilvers J et al. (2014) Towards a reflexive turn in the governance of global environmental expertise. The cases of the IPCC and the IPBES. GAIA 23:80-87

Bednarek AT, Wyborn C, Cvitanovic C et al. (2018) Boundary spanning at the science-policy interface: the practitioners' perspectives. Sustain Sci 13:1175-1183

Beierle TC, Cayford J (2002) Democracy in practice: public participation in environmental decisions. Routledge, Abingdon

Bertozzi AL, Franco E, Mohler G et al. (2020) The challenges of modeling and forecasting the spread of COVID-19. Proc Natl Acad Sci USA 117:16732-16738

Boswell J (2018) Keeping expertise in its place: understanding arm's-length bodies as boundary organisations. Policy Politics 46:485-501

Cairney P (2016) The politics of evidence-based policy making. Palgrave Macmillan, Basingstoke

Cartwright N, Hardie J (2012) Evidence-based policy: a practical guide to doing it better. Oxford University Press, Oxford

Cerna L (2013) The nature of policy change and implementation: a review of different theoretical approaches. OECD, Paris

Davies W (2016) The age of post-truth politics. N Y Times https://www.nytimes com/2016/08/24/opinion/campaign-stops/the-age-of-post-truth-politics. html. Accessed 31 Aug 2020.

Davies W (2018) Nervous states: how feeling took over the world. Penguin Random House, London

De Solla Price DJ (1963) Little science, big science. Columbia University Press, New York

Dias S, Sutton AJ, Ades AE, Welton NJ (2013) Evidence synthesis for decision making 2: a generalized linear modeling framework for pairwise and network meta-analysis of randomized controlled trials. Med Decis Mak 33:607-617

Douglas HE (2000) Inductive risk and values in science. Philos Sci 67:559-579

Douglas HE (2009) Science, policy, and the value-free ideal. University of Pittsburgh Press, Pittsburgh

Ennser-Jedenastik L (2016) The politicization of regulatory agencies: between partisan influence and formal independence. J Public Adm Res Theory 26:507-518

Funtowicz S, Ravetz JK (1993) Science for the post-normal age. Futures 25:739-755

Gethmann CF, Carrier M, Hanekamp G, Kaiser M, Kamp G, Lingner S, Quante M, Thiele F (2015) Interdisciplinary research and trans-disciplinary validity claims. Springer, Basel

Gibbons M (ed) (1994) The new production of knowledge: the dynamics of science and research in contemporary societies. SAGE, Newcastle upon Tyne

Gluckman P (2014) Policy: the art of science advice to government. Nature 507:163-165

Gluckman P (2017) Enhancing evidence-informed policy making. Office of the Prime Minister's Chief Science Advisor, Auckland

Gluckman P (2018) The role of evidence and expertise in policy-making: the politics and practice of science advice. J Proc R Soc NSW 151:91-101

Gough D, Thomas J, Oliver S (2019) Clarifying differences between reviews within evidence ecosystems. Syst Rev 8:170

Grundmann R (2017) The problem of expertise in knowledge societies. Minerva $55: 25-48$

Guston DH (2000) Retiring the social contract for science. Issues Sci Technol 16: Summer 2000

Hallsworth M, Parker S, Rutter J (2011) Policy making in the real world: evidence and analysis. Institute for Government, London

Hilgartner S (2000) Science on the stage: expert advice as public drama. Stanford University Press, Stanford

Hilgartner S (2004) The credibility of science on stage. Soc Stud Sci 34:443-452

Höpfl HM (2006) Post-bureaucracy and Weber's "modern" bureaucrat. J Organ Change Manag 19:8-21

Hoppe R (1999) Policy analysis, science and politics: from 'speaking truth to power' to 'making sense together'. Sci Public Policy 26:201-210

Hoppe R (2005) Rethinking the science-policy nexus: from knowledge utilization and science technology studies to types of boundary arrangements. Poiesis Praxis 3:199-215

Hunter DJ (2016) Evidence-informed policy: in praise of politics and political science. Public Health Panor 2:268-272

International Network For Government Science Advice (2020) Science advice and COVID-19. https://www.ingsa.org/covid/. Accessed 31 Aug 2020.

Jasanoff S (1994) The fifth branch: science advisers as policymakers. Harvard University Press, Cambridge

Jasanoff S (2003) (No?) Accounting for expertise. Sci Public Policy 30:157-162 
Jasanoff S (ed.) (2004) States of knowledge: the co-production of science and social order. Routledge, London

Jasanoff S (2006) Transparency in public science: purposes, reasons, limits. Law Cont Probl 69:21-45

Jasanoff S, Wynne B (1998) Science and decision making. In: Rayner S, Malone E (eds) Human choice and climate change, vol 1: the societal framework. Battelle, Columbus, pp 1-88

Joyner BL, Gill-Bailey C, Moon RY (2009) Infant sleep environments depicted in magazines targeted to women of childbearing age. Pediatrics 124:e416-22

Kohler PM (2020) Science advice and global environmental governance: expert institutions and the implementation of international environmental treaties. Anthem Press, London

Kropp C, Wagner J (2010) Knowledge on stage: scientific policy advice. Sci Technol Hum Values 35:812-838

Kupferschmidt K (2020) Preprints bring 'firehose' of outbreak data. Science 367:963-964

Lemos MC, Morehouse BJ (2005) The co-production of science and policy in integrated climate assessments. Glob Environ Chang 15:57-68

Lewis P (2020) Legal provision for crisis preparedness: foresight not hindsight. Chatham House

Mair D, Smillie L, La Placa G et al. (2019) Understanding our political nature: how to put knowledge and reason at the heart of political decision-making. JRC, Luxembourg

Marmot MG (2004) Evidence based policy or policy based evidence? BMJ 328:906-907

Matthews D (2020) German humanities scholars enlisted to end coronavirus lockdown. Times Higher Education. https://www.timeshighereducation.com/ news/german-humanities-scholars-enlisted-end-coronavirus-lockdown. Accessed 31 Aug 2020

McIntyre L (2018) Post-truth. MIT Press, Cambridge

Metzler K (2020) What social science can offer us in a time of Covid-19. Times Higher Education. https://www.timeshighereducation.com/blog/what-socialscience-can-offer-us-time-covid-19. Accessed 25 Aug 2020

Michaels S (2009) Matching knowledge brokering strategies to environmental policy problems and settings. Environ Sci Policy 12:994-1011

Miller S (2001) Public understanding of science at the crossroads. Public Underst Sci 10:115-120

Moon RY, Task Force On Sudden Infant Death Syndrome (2016) SIDS and other sleep-related infant deaths: evidence base for 2016 updated recommendations for a safe infant sleeping environment. Pediatrics 138:e20162940

National Academies Of Sciences, Engineering, And Medicine, Committee on The Science of Science Communication (2017) Communicating science effectively: a research agenda. National Academies Press, Washington

OECD (2015) Scientific advice for policy making: The role and responsibility of expert bodies and individual scientists. OECD Science, Technology and Industry Policy Papers. OECD, Paris

OECD (2018) Scientific advice during crises: facilitating transnational co-operation and exchange of information. OECD Global Science Forum, Paris

Office of the Prime Minister's Science Advisory Committee (2014) Synthesis report: science advice to governments conference. Office of the Prime Minister's Science Advisory Committee, Auckland

Oldham G, Mclean R (1997) Approaches to knowledge-brokering. International Institute for Sustainable Development (IISD)

Oliver K, Cairney P (2019) The dos and don'ts of influencing policy: a systematic review of advice to academics. Palgrave Commun 5:Article number 21

Oreskes N, Conway EM (2010) Merchants of doubt: how a handful of scientists obscured the truth on issues from tobacco smoke to global warming. Bloomsbury Publishing, London

Owens S (2012) Experts and the environment: The UK Royal Commission on environmental pollution 1970-2011. J Environ Law 24:1-22

Parkhurst J (2017) The politics of evidence: from evidence-based policy to the good governance of evidence. Routledge, London and New York

Pielke R (2007) The honest broker. Cambridge University Press, Cambridge

Pielke R (2015) Five modes of science engagement. Roger Pielke Jr.'s Blog: Science, Innovation, Politics. http://rogerpielkejr.blogspot.com/2015/01/five-modesof-science-engagement.html. Accessed 31 Aug 2020

Pierson S (2012) Science advocacy: what is it and what is the role of professional societies? AMSTAT News, 1 January 2012

Pitt MB, Berger JN, Sheehan KM (2016) Compliance of parenting magazines advertisements with american academy of pediatrics recommendations. Children 3:23

Rudner R (1953) The scientist qua scientist makes value judgements. Philos Sci 20 (1):1-6
Ruggeri K, Van Der Linden S, Wang C et al. (2020) Standards for evidence in policy decision-making. Nature Research Social and Behavioural Sciences 399005

Rushefsky M (1984) The misuse of science in governmental decisionmaking. Sci Technol Hum Values 9:47-59

Scheufele DA (2014) Science communication as political communication. Proc Natl Acad Sci USA 111(Suppl 4):13585-13592

Scheufele DA, Krause NM (2019) Science audiences, misinformation, and fake news. Proc Natl Acad Sci USA 116:7662-7669

Sharman A, Holmes J (2010) Evidence-based policy or policy-based evidence gathering? Biofuels, the EU and the 10\% target. Environ Policy Gov 20:309-321

Speed E, Mannion R (2017) The rise of post-truth populism in pluralist liberal democracies: challenges for health policy. Int J Health Policy Manag 6:249-251

Stenek NH (2011) Responsible advocacy in science: standards, benefits and risks. Workshop on Advocacy in Science. AAAS Scientific Responsibility, Human Rights and Law Program, Washington

Topp L, Mair D, Smillie L, Cairney P (2018) Knowledge management for policy impact: the case of the European Commission's Joint Research Centre. Palgrave Commun 4:87

Tushman ML, Scanlan TJ (2017) Boundary spanning individuals: their role in information transfer and their antecedents. Acad Manag Ann 24:289-305

Tyler C, Gluckman P (2020) Coronavirus: governments knew a pandemic was a threat-here's why they weren't better prepared. The Conversation, 28 April 2020

Van Der Sluijs JP, Craye M, Funtowicz S et al. (2005) Combining quantitative and qualitative measures of uncertainty in model-based environmental assessment: the NUSAP system. Risk Anal 25:481-492

Weingart P (1999) Scientific expertise and political accountability: paradoxes of science in politics. Sci Public Policy 26:151-161

Welton NJ (2012) Evidence synthesis for decision making in healthcare. John Wiley \& Sons, Chichester

Williams P (2002) The competent boundary spanner. Public Admin 80:103-124

Zhang L, Zhao W, Sun B et al. (2020) How scientific research reacts to international public health emergencies: a global analysis of response patterns. Scientometrics 124:747-773

Zhao ZJ, Anand J (2013) Beyond boundary spanners: the 'collective bridge' as an efficient interunit structure for transferring collective knowledge. Strateg Manag J 34:1513-1530

\section{Acknowledgements}

MK was supported by the Norman Barry Trust visiting fellowship to the University of Auckland.

\section{Competing interests}

The authors declare no competing interests.

\section{Additional information}

Correspondence and requests for materials should be addressed to P.D.G.

Reprints and permission information is available at http://www.nature.com/reprints

Publisher's note Springer Nature remains neutral with regard to jurisdictional claims in published maps and institutional affiliations.

Open Access This article is licensed under a Creative Commons Attribution 4.0 International License, which permits use, sharing, adaptation, distribution and reproduction in any medium or format, as long as you give appropriate credit to the original author(s) and the source, provide a link to the Creative Commons license, and indicate if changes were made. The images or other third party material in this article are included in the article's Creative Commons license, unles indicated otherwise in a credit line to the material. If material is not included in the article's Creative Commons license and your intended use is not permitted by statutory regulation or exceeds the permitted use, you will need to obtain permission directly from the copyright holder. To view a copy of this license, visit http://creativecommons.org/ licenses/by/4.0/.

(C) The Author(s) 2021 